\title{
Clinical Efficacy and Quality of Life Asse
Partial Cystectomy and Plasmakinetic Transurethral Resection of Tumor in Bladder Cancer Patients
}

\author{
Zhi-Jia Li' \\ Da-Ya Wang' \\ Zhi-Hu Liu (1) ${ }^{2}$ \\ 'Department of Urology, Wenzhou \\ Central Hospital, Wenzhou, Zhejiang, \\ 325000, People's Republic of China; \\ ${ }^{2}$ Department of Urology, Bei Da Huang \\ Industry Group General Hospital, Harbin, \\ Heilongjiang, 150088, People's Republic \\ of China
}

\begin{abstract}
Objective: Bladder cancer is a common malignant tumor of the urinary system, with an incidence ranking the first in the urinary system. Without timely and effective treatment, the tumor may spread to other parts of the body. Traditional partial cystectomy (PC) and plasmakinetic transurethral resection of bladder tumor (PKRBT) are common surgical methods for superficial bladder cancer (SBC). This study aims to clarify the clinical efficacy of bladder carcinoma (BC) patients treated by either PC or PKRBT and their effects on the quality of life (QOL) of patients.
\end{abstract}

Methods: A total of 142 patients with SBC treated in Wenzhou Central Hospital and Bei da huang Industry Group General Hospital from March 2018 to June 2020 were analyzed retrospectively. According to the surgical method, patients undergoing PKRBT were included in the research group $(\mathrm{n}=74)$ while those treated by PC were included in the control group $(n=69)$. Surgical indicators (intraoperative blood loss, IBL; operating time, OT; bladder irrigation time; catheter retention time; length of hospital stay, LOS), postoperative complication rate, and one-year recurrence rate were compared between the two groups. Besides, the levels of inflammatory factors [tumor necrosis factor (TNF)- $\alpha$, interleukin (IL)-6, IL-8, IL-10], psychological and emotional scores (Self-Rating Anxiety Scale, SAS; Self-Rating Depression Scale, SDS), and living conditions (Pittsburgh Sleep Quality Index, PSQI) before and after treatment were compared.

Results: Compared with the control group, patients in the research group had 1) less IBL, less time of OT, bladder irrigation and indwelling catheter time, as well as shorter postoperative LOS; 2) lower contents of inflammatory factors TNF- $\alpha$, IL-6 and IL-8, and higher IL-10; 3) lower SAS and SDS scores and higher PSQI; and 4) fewer postoperative complications and lower one-year recurrence rate.

Conclusion: Compared with PC, PKRBT contributes to higher efficacy and better postoperative QOL in patients SBC.

Keywords: partial cystectomy, plasmakinetic transurethral resection of bladder tumor, superficial bladder cancer, inflammatory factors, SAS, SDS, PSQI

\section{Introduction}

Bladder tumors are primary malignancies associated with bladder urothelium, with an incidence ranking the first in urogenital tumors in China while following only prostate cancer in foreign countries; Moreover, the disease has a predilection for men, especially among the elderly. ${ }^{1-4}$ According to Global Cancer Statistics, there
Department of Urology, Bei Da Huang Industry Group General Hospital,

No. 235, Hashuang Road, Nangang

District, Harbin, Heilongjiang, I50088,

People's Republic of China

Tel +86-15804508010

Email liuzhihu208@I63.com 
were 573,278 new cases of bladder cancer (BC) and 212,536 associated deaths in $2020 .^{5}$ With the aggravation of population aging, the incidence of $\mathrm{BC}$ remains stubbornly high. ${ }^{6}$ The main presentations are urinary tract obstruction, dysuria, etc., which will cause other uncomfortable symptoms, seriously influencing the normal life of patients. Without timely treatment, tumor cells will also spread to rectum, liver, kidney, pelvic cavity and uterus, increasing the difficulty of treatment. ${ }^{7,8}$ The main risk factors of $\mathrm{BC}$ identified so far include environmental and occupational exposure to chemical carcinogens such as tobacco smoke and metabolites, aromatic hydrocarbons, house paints, fungicides, plastics and heavy metals. ${ }^{9-12}$ In addition, people with a family history of $\mathrm{BC}$ have twice the risk of developing BC; However, bladder tumors affected by family history are not common, and no genes with high penetrance rates have been found yet. ${ }^{13}$

Non-muscle invasive bladder cancer (NMIBC), also called low-grade urothelial neoplasia, is predominant in $\mathrm{BC}$ patients, accounting for about $85 \%$ of all the cases. Such tumors can be multifocal and have a risk of recurrence after local resection, but usually do not invade the bladder wall or metastasize. ${ }^{14,15}$ Solid non-papillary tumors invading the detrusor, known as muscle invasive bladder cancer (MIBC), occur in 20\%-25\% of patients; They arise from carcinoma in situ (CIS) or severe dysplasia, and are very likely to cause distant metastasis, which are therefore called high-grade urothelial neoplasia. ${ }^{16}$

Currently, the major clinical treatment methods for BC include surgical and non-surgical treatments. NMIBC is a superficial tumor. Due to the heterogeneity of tumor surface and differences in the natural process of tumor, NMIBC has a high recurrence rate and the risk of deep progression. Therefore, the main therapeutic goals of NMIBC include eliminating existing diseases, inhibiting tumor growth, reducing recurrence rate, preventing tumors from developing into myometrial infiltration or distant metastasis, and lowering mortality. Therefore, radical cystectomy is the first-line treatment for BC. ${ }^{17,18}$ The common clinical treatment methods include transurethral resection of bladder tumor and partial cystectomy (PC). Due to the advantages of low trauma and high safety, transurethral resection of bladder tumor has gradually replaced the traditional PC to become the mainstream treatment in clinical application. However, nearly 50\%$80 \%$ of patients experienced bladder tumor recurrence after transurethral resection. ${ }^{19}$ The main forms of recurrence after NMIBC resection are in situ recurrence and ectopic recurrence, among which ectopic recurrence is more common. Thus, more efficient and thorough treatment methods with a higher safety profile are needed.

In recent years, with the rapid development of medicine, the treatment of $\mathrm{BC}$ has entered the era of minimally invasive treatment. Plasmakinetic transurethral resection of bladder tumor (PKRBT) is not only an important means to diagnose $\mathrm{BC}$, but also the main treatment plan that can achieve the goal of radical cure of $\mathrm{BC}^{20}$ Traditional PC, a common surgical method albeit, ${ }^{21}$ causes great pain to patients in the course of treatment, with a relatively high rate of postoperative complications and recurrence. Therefore, PKRBT, which is more efficient, thorough and safer, has gradually become the preferred clinical treatment. Currently, most of the research on the efficacy of surgery on $\mathrm{BC}$ is limited to the success rate and postoperative complications, while paying little attention to the physical and mental status of patients. Thus, the novelty of our study is to retrospectively discuss the effects of the two surgical modalities on $\mathrm{BC}$ patients from the aspects of clinical efficacy, psychological mood and quality of life (QOL).

\section{Materials and Methods Study Population}

All the clinical data of $142 \mathrm{BC}$ patients treated in Wenzhou Central Hospital and Bei da huang Industry Group General Hospital between March 2018 and June 2020 were collected for retrospective analysis. They were assigned to a control group $(n=69)$ and a research group $(n=74)$ based on differences in surgical modalities. Inclusion criteria: The patients were diagnosed as NMIBC by color Doppler ultrasound, cystoscopy or intravenous pyelography and biopsy; The clinical stage was T2N0M0; Normal hepatorenal function; Karnofsky Performance Scoring $(\mathrm{KPS})^{22} \geq 70$ points; Normal bone marrow haematopoietic function; No major systemic organ injury. Exclusion criteria: Liver and kidney dysfunction; Serious cardiac insufficiency; Abnormal coagulation function; Poor compliance; Surgical contraindications; Hematological system diseases; Other malignancies. The two arms showed comparable clinical data with no significant differences $(\mathrm{P}>0.05$, Table 1). Ethical approval was obtained from the Institutional Review Board of Wenzhou Central Hospital and Bei da huang Industry Group General Hospital. All patients were informed about this study and signed an informed consent form voluntarily. This study 
Table I General Information

\begin{tabular}{|c|c|c|c|c|}
\hline & Control Group $(n=69)$ & Research Group $(n=74)$ & $\chi^{2} / t$ & $\mathbf{P}$ \\
\hline Gender [n(\%)] & & & 0.01872 & 0.8912 \\
\hline Male & $44(63.77)$ & $48(64.86)$ & & \\
\hline Female & $25(36.23)$ & $26(35.14)$ & & \\
\hline Average age (years) & $61.35 \pm 3.02$ & $62.19 \pm 3.48$ & 1.5368 & 0.1266 \\
\hline BMI $\left(\mathrm{kg} / \mathrm{m}^{2}\right)$ & $21.45 \pm 1.38$ & $21.69 \pm 1.51$ & 0.9899 & 0.3239 \\
\hline Course of disease (year) & $4.34 \pm 0.39$ & $4.3 I \pm 0.44$ & 0.4303 & 0.6676 \\
\hline Tumor diameter $(\mathrm{cm})$ & $\mathrm{I} .8 \mathrm{I} \pm 0.23$ & $1.83 \pm 0.26$ & 0.4858 & 0.6278 \\
\hline Tumor staging & & & 0.4604 & 0.4974 \\
\hline 1 & $40(57.97)$ & $47(63.5 \mathrm{I})$ & & \\
\hline II & $29(42.03)$ & 27 (36.49) & & \\
\hline Pathological grading & & & 0.4178 & 0.5180 \\
\hline GI & $45(65.22)$ & $52(70.27)$ & & \\
\hline G2 & $24(34.78)$ & $22(29.73)$ & & \\
\hline Symptom & & & 1.0753 & 0.7831 \\
\hline Odynuria & $31(44.93)$ & $37(50.00)$ & & \\
\hline Incomplete bladder emptying & I8 (26.09) & $14(18.92)$ & & \\
\hline Sychnuria & II (I5.94) & $13(17.57)$ & & \\
\hline Microscopic hematuria & $9(13.04)$ & $10(13.5 I)$ & & \\
\hline
\end{tabular}

was conducted in accordance with the Declaration of Helsinki.

\section{Sample Size Calculation}

Sample size was calculated using normal approximation analysis of PASS 15.0 to analyze the difference between two-independent equal groups, with power of $80 \%$ and alpha error of 0.05 , yielding a total sample size of 136 (68 patients in each group) at least.

\section{Surgical Methods}

Patients in the control group underwent PC. A catheter was reserved for the patient preoperatively so that he/she can urinate after surgery. The patient was placed in the supine position with continuous epidural anesthesia or inhalation general anesthesia. Then, an incision was made in the suprapubic midline, and the patient's bladder was opened so that the tumor could be exposed to the field of vision to facilitate removal. The excision area was $2-3 \mathrm{~cm}$ beyond the external diameter of the lesion, and the adherent peritoneum was excised. For patients whose lesions were located at the ureter orifice, the lower ureter and ureter orifice were removed, and the ureter was then re-sutured to the normal part of the patient's bladder wall. After removal, the bladder was flushed with sterile distilled water, a drainage tube was placed, and the abdomen was closed. The bladder was perfused with
$40 \mathrm{~mL}$ saline mixed with $20 \mathrm{mg}$ hydroxycamptothecin after surgery.

PKRBT was performed on patients in the research group. Patients in the lithotomy position received continuous epidural anesthesia or inhalation general anesthesia. Gyrus plasma electrocutting system (UK, electric cutting power $100-140 \mathrm{~W}$, electric coagulation power $60-80 \mathrm{~W}$ ) was adopted, and $0.9 \%$ normal saline was used as the washing solution. The surgery was performed on a television imaging system. First, the location, size, number and infiltration of the tumor were observed. In addition, the presence of pedicled small tumors was determined and if so, the relationship between the pedicle and the ureteral orifice was observed. Then, the tumor body and pedicle were removed successively from far to near with the bipolar electric knife. The cutting temperature was lower than $90^{\circ} \mathrm{C}$, the resection scope included 1$2 \mathrm{~cm}$ of normal mucosa around the tumor, and the resection depth reached the muscle layer. The tissue fragments and blood clots were flushed out of the body with an irrigator after complete hemostasis. The postoperative perfusion treatment was the same as the control group.

All patients were followed up for one year.

\section{Outcome Measures}

(1) Clinical index observation: Intraoperative blood loss (IBL), operating time (OT), bladder irrigation time, 
indwelling catheter time and postoperative length of hospital stay (LOS) of the two arms were recorded.

(2) Contents of Inflammatory factors: $:^{23} 4 \mathrm{~mL}$ of fasting venous blood was collected from all patients in the early morning before and 7 days after surgery, and centrifuged. The serum was collected to determine the levels of inflammatory factors tumor necrosis factor- $\alpha$ (TNF- $\alpha$ ), interleukin (IL)6 , IL- 8 and IL-10 by ELISA. All the kits were purchased from Sangon Biotech (Shanghai) Co., Ltd., and all operations were carried out in strict accordance with relevant instructions.

(3) Sleep quality: The Pittsburgh Sleep Quality Index $(\mathrm{PSQI})^{24}$ was used to score the sleep quality of patients before and 7 days after surgery. The PSQI was composed of 19 self-rated and 5 other-rated items, but the 19th selfrated item and the 5 th other rated item were excluded from the scoring range, that is, there were 18 items involved in the scoring. The 18 items were divided into 7 parts, with each part scored on a scale of $1-3$. The accumulated scores of each part were the total score (1-21 points). Lower scores indicated better sleep quality.

(4) Incidence of complications: The incidence of postoperative complications occurred in the two arms was compared, including postoperative infection, cysthemorrhagia, cystospasm and urethrostenosis.

(5) Adverse emotions: Patients' anxiety and depressive symptoms were assessed by the Self rating Anxiety Scale $(\mathrm{SAS})^{25}$ and the Self rating depression scale (SDS) ${ }^{26}$ before and 6 months after surgery. There were 20 items in each scale based on a 1-4 point system, with higher scores indicating severe symptoms of patients.

(6) Quality of life (QOL): ${ }^{27}$ The 36-Item Short-Form Health Survey (SF-36) was used to evaluate patients' QOL from the aspects of physical functioning (PF), rolephysical (RP), bodily pain (BP), social functioning (SF), vitality (VT), role-emotional (RE), mental health $(\mathrm{MH})$ and general health $(\mathrm{GH})$ during the 1-year follow-up.
The score of each dimension was 100 points, and higher scores indicated better QOL.

(7) Recurrence rate: Patients were followed up for one year, and the incidence of recurrence was counted.

\section{Statistical Processing}

Data were processed by SPSS 21.0 statistical software (IBM, Armonk, NY, USA). Measurement data were expressed as Mean $\pm \mathrm{SD}$ and compared by the $t$ test. Count data, represented by $\mathrm{n}(\%)$, were analyzed by the Chi-square test. The differences between the mean values were analyzed by one-way, two-factor or three-factor analysis of variance (ANOVA), with or without repeated measures, followed by Bonferroni correction (Bonferroni post-hoc analysis). With $\alpha=0.05$ as the test standard, the difference with $\mathrm{P}<0.05$ was considered significant.

\section{Results}

\section{Clinical Indicators of Two Arms}

Compared with the control group, patients in the research group had significantly better clinical indicators after PKRBT, less IBL, and shorter OT, bladder irrigation time, indwelling catheter time as well as postoperative LOS (all $\mathrm{P}<0.05$ ), Table 2 .

\section{Comparison of Inflammatory Factors}

The serum levels of inflammatory factors were compared between the two arms before and 7 days after surgery. The results showed no significant difference in TNF- $\alpha$, IL-6, IL-8 and IL-10 between the two arms before operation $(\mathrm{P}>0.05)$. After operation, TNF- $\alpha$, IL- 6 and IL-8 in both arms showed a significant downward trend compared with those before operation, while IL-10 showed an upward trend, with statistically significant differences between the research group and the control group $(\mathrm{P}<0.05)$, Figure 1 .

Table 2 Clinical Indicators of Two Groups of Patients

\begin{tabular}{|c|c|c|c|c|c|}
\hline & $\begin{array}{c}\text { Intraoperative } \\
\text { Blood Loss (mL) }\end{array}$ & $\begin{array}{c}\text { Operating } \\
\text { Time (min) }\end{array}$ & $\begin{array}{c}\text { Bladder } \\
\text { Irrigation Time } \\
\text { (min) }\end{array}$ & $\begin{array}{l}\text { Urinary Catheter } \\
\text { Indwelling Time (d) }\end{array}$ & $\begin{array}{l}\text { Postoperative Length of } \\
\text { Hospital Stay (d) }\end{array}$ \\
\hline Control group $(n=69)$ & $46.5 \pm 5.8$ & $71.6 \pm 9.8$ & $36.7 \pm 6.6$ & $7.2 \pm 1.3$ & $12.7 \pm 3.4$ \\
\hline Research group $(n=74)$ & $23.7 \pm 3.5$ & $45.3 \pm 5.6$ & $16.7 \pm 4.3$ & $4.6 \pm 0.7$ & $6.9 \pm 2.1$ \\
\hline$\chi^{2} / t$ & 28.6802 & 19.8703 & 21.6113 & 15.0284 & 12.3634 \\
\hline$P$ & $<0.0001$ & $<0.0001$ & $<0.0001$ & $<0.0001$ & $<0.0001$ \\
\hline
\end{tabular}

Note: Data in bold indicates that the difference is statistically significant. 
A
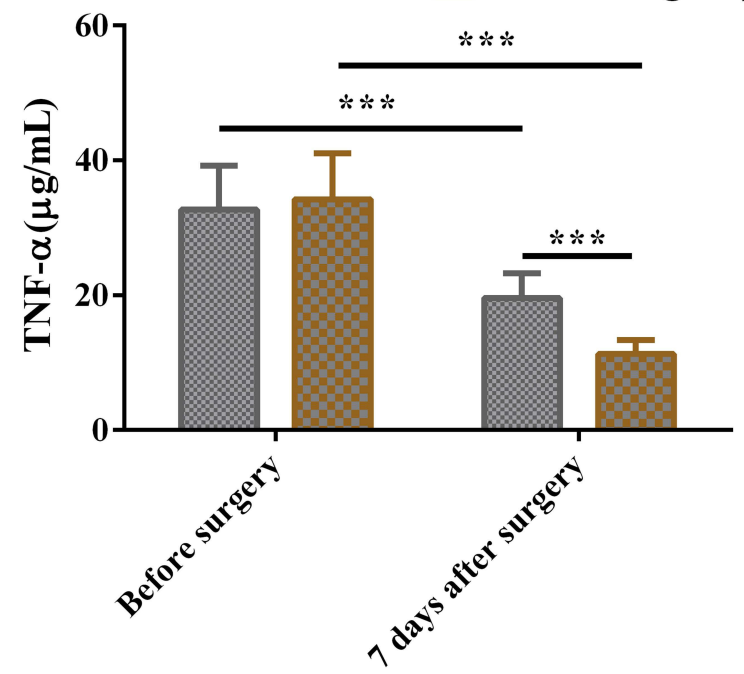

C

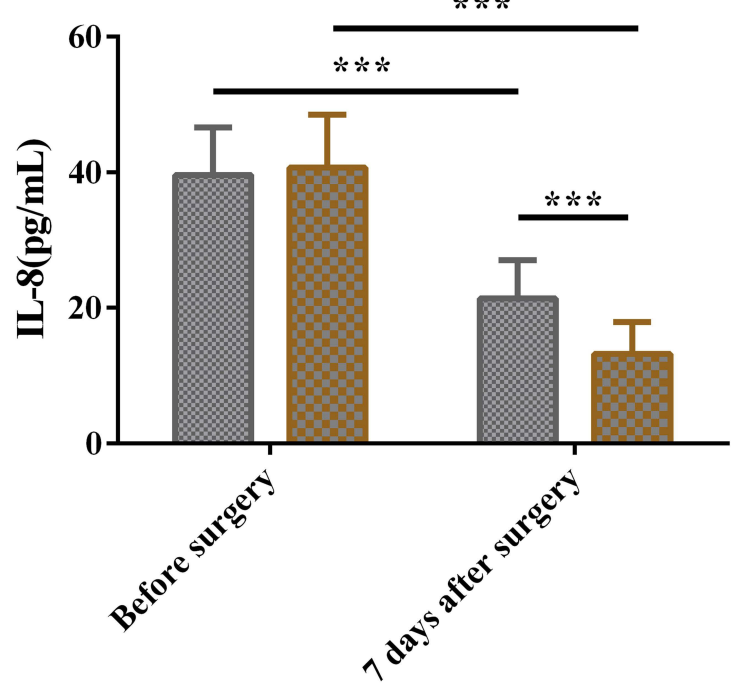

B

Control group

Research group
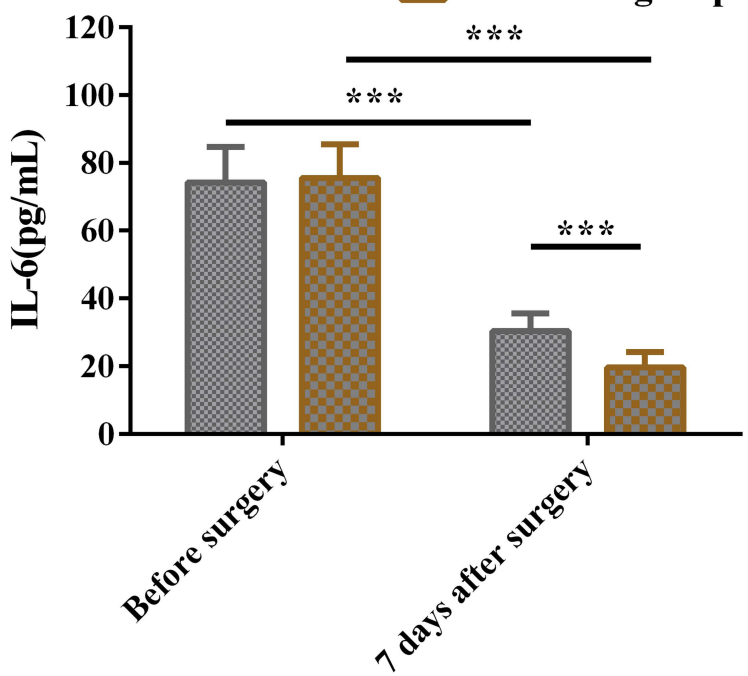

D
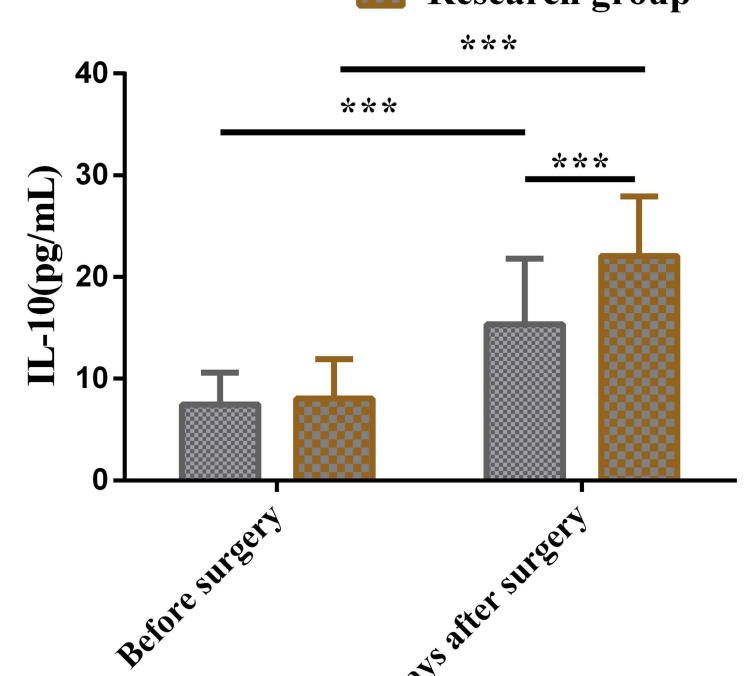

Control group

Research group

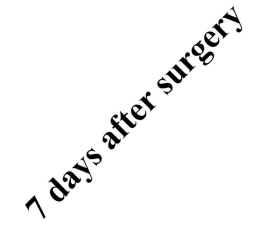

Figure I Comparison of inflammatory factors between two groups. (A) TNF- $\alpha$ level; (B) IL-6 level; (C) IL-8 level; (D) IL-10 level; ***P<0.05.

\section{Sleep Quality of Two Arms}

The PSQI score, which differed insignificantly between the research group and the control group before operation ( $\mathrm{P}>0.05)$, reduced in both arms 7 days after operation, with a lower score in the research group $(\mathrm{P}<0.05)$, Table 3.

\section{Adverse Emotions in Two Arms}

Both SAS and SDS scores decreased significantly in both groups after surgery, and were even lower in the research group compared with the control group $(\mathrm{P}<0.05)$, Figure 2.

\section{QOL in Two Arms}

After one year's follow-up, the two arms were compared in terms of QoL from PF, RP, BP, SF, VT, RE, MH, and $\mathrm{GH}$. The results showed that the scores of all dimensions, which were not significantly different between the two groups before treatment $(\mathrm{P}>0.05)$, showed an upward trend at the one-year follow-up, and the scores were even 
Table 3 Comparison of PSQI Scores Between Two Groups

\begin{tabular}{|l|c|c|c|c|}
\hline & Before Operation & 7 Days After Operation & $\chi^{2} / \mathbf{t}$ & P \\
\hline Control group $(n=69)$ & $8.68 \pm 2.14$ & $5.06 \pm 1.63$ & 11.1781 & $<0.0001$ \\
Research group $(n=74)$ & $8.42 \pm 2.37$ & $1.88 \pm 0.57$ & 23.0799 & $<0.0001$ \\
$\chi^{2 / t}$ & 0.6868 & 15.7827 & & \\
$P$ & 0.4933 & $<0.0001$ & & \\
\cline { 2 - 5 }
\end{tabular}

Note: Data in bold indicates that the difference is statistically significant.

higher in the research group compared with the control group $(\mathrm{P}<0.05)$, Table 4 .

\section{Complications and One-Year Recurrence Rate of Two Arms}

After different surgical treatments, the incidence of complications was $21.74 \%$ in the control group and $9.46 \%$ in the research group, and the one-year recurrence rate was $29.73 \%$ in the research group and $46.38 \%$ in the control group $(\mathrm{P}<0.05)$, Table 5 . The research group outperformed the control group in terms of the incidence rates of complications and one-year recurrence.

\section{Discussion}

Clinically, the radical treatment of malignant tumors is mainly based on total resection, which can effectively avoid disease recurrence caused by lymph node metastasis and distant metastasis, thus improving the survival of patients. ${ }^{28}$ However, the QOL of some patients, especially elderly patients, is reduced due to the loss of function caused by total organ resection. As to this problem, some scholars put forward that it is feasible to

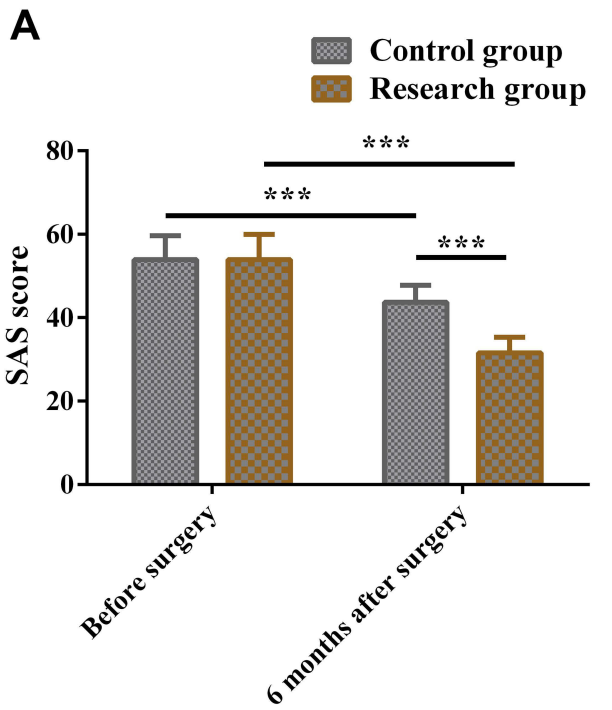

perform partial resection for cancer patients during radical operation, supplemented with postoperative chemotherapy to avoid the spread of cancer cells, which can effectively preserve the organ function of patients, reduce the effect of operation on their QOL, and achieve the purpose of radical treatment. ${ }^{29}$ The PKRBT resection system is a bipolar electrode, with selfcontrolled working and loop electrodes. The high-frequency current forms an electromagnetic field through conductive normal saline, which is finally converted into macromolecules in target tissue decomposition organisms. ${ }^{30} \mathrm{PC}$ and PKRBT are two surgical methods that can effectively preserve the bladder function of patients while achieving radical resection of tumor tissues. This study mainly observes the clinical efficacy of these two surgical modalities in patients with BC.

In this study, it was found that PKRBT was associated with less IBL, shorter OT, bladder irrigation time, indwelling catheter time, and postoperative LOS compared with PC, suggesting that PKRBT had better efficacy. The main reason is that PKRBT applies high frequency current of the two electrodes to excited the $\mathrm{NaCl}$ solution to break the chemical bonds, hydrogen bonds, ion bonds in the macromolecules to form

B
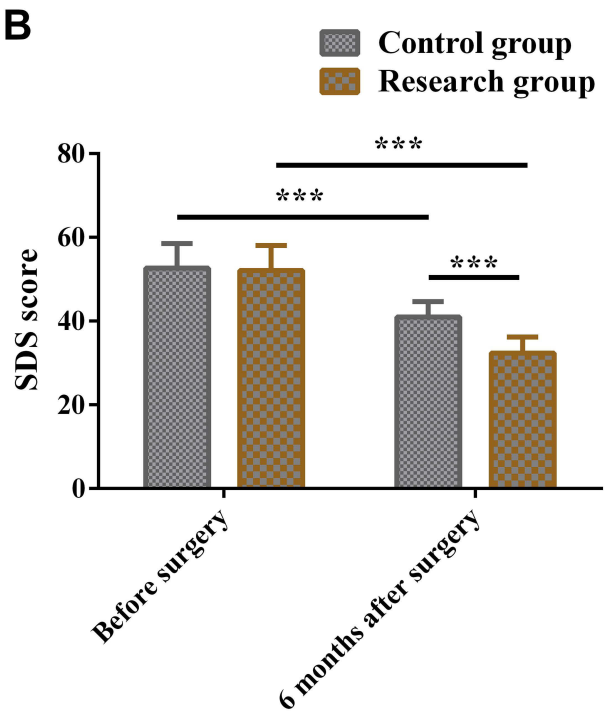

Figure 2 Comparison of SAS and SDS scores between two groups. (A) SAS score; (B) SDS score; ***P<0.05. 
Table 4 Comparison of Quality of Life Between Two Groups

\begin{tabular}{|c|c|c|c|c|c|c|c|c|}
\hline & \multicolumn{2}{|c|}{ Physical Functioning } & \multicolumn{2}{|c|}{ Role-Physical } & \multicolumn{2}{|c|}{ Bodily Pain } & \multicolumn{2}{|c|}{ Social Functioning } \\
\hline & $\begin{array}{c}\text { Before } \\
\text { Operation }\end{array}$ & $\begin{array}{c}\text { One Year } \\
\text { After } \\
\text { Operation }\end{array}$ & Skill & $\begin{array}{c}\text { One Year } \\
\text { After } \\
\text { Operation }\end{array}$ & $\begin{array}{c}\text { Before } \\
\text { Operation }\end{array}$ & $\begin{array}{c}\text { One Year } \\
\text { After } \\
\text { Operation }\end{array}$ & $\begin{array}{c}\text { Before } \\
\text { Operation }\end{array}$ & $\begin{array}{c}\text { One Year } \\
\text { After } \\
\text { Operation }\end{array}$ \\
\hline $\begin{array}{l}\text { Control } \\
\text { group } \\
(n=69)\end{array}$ & $64.36 \pm 5.68$ & $80.66 \pm 7.32$ & $63.84 \pm 5.98$ & $81.34 \pm 5.63$ & $60.25 \pm 5.57$ & $81.04 \pm 5.36$ & $65.31 \pm 6.74$ & $84.39 \pm 7.68$ \\
\hline $\begin{array}{l}\text { Research } \\
\text { group } \\
(n=74)\end{array}$ & $65.02 \pm 6.49$ & $83.74 \pm 6.59$ & $64.38 \pm 6.13$ & $84.67 \pm 6.19$ & $61.17 \pm 5.72$ & $84.31 \pm 6.11$ & $65.76 \pm 7.05$ & $87.83 \pm 7.49$ \\
\hline$\chi^{2 / t}$ & 0.6452 & 2.6475 & 0.5326 & 3.3575 & 0.9733 & 3.4024 & 0.3896 & 2.7110 \\
\hline \multirow[t]{3}{*}{$P$} & 0.5198 & 0.0090 & $0.595 I$ & 0.0010 & 0.3321 & 0.0008 & 0.6974 & 0.0075 \\
\hline & \multicolumn{2}{|c|}{ Vitality } & \multicolumn{2}{|c|}{ Role-Emotional } & \multicolumn{2}{|c|}{ Mental Health } & \multicolumn{2}{|c|}{ General Health } \\
\hline & $\begin{array}{c}\text { Before } \\
\text { Operation }\end{array}$ & $\begin{array}{c}\text { One Year } \\
\text { After } \\
\text { Operation }\end{array}$ & $\begin{array}{c}\text { Before } \\
\text { Operation }\end{array}$ & $\begin{array}{c}\text { One Year } \\
\text { After } \\
\text { Operation }\end{array}$ & $\begin{array}{c}\text { Before } \\
\text { Operation }\end{array}$ & $\begin{array}{c}\text { One Year } \\
\text { After } \\
\text { Operation }\end{array}$ & $\begin{array}{c}\text { Before } \\
\text { Operation }\end{array}$ & $\begin{array}{c}\text { One Year } \\
\text { After } \\
\text { Operation }\end{array}$ \\
\hline $\begin{array}{l}\text { Control } \\
\text { group } \\
(n=69)\end{array}$ & $60.28 \pm 5.77$ & $82.6 I \pm 6.05$ & $63.54 \pm 5.78$ & $82.67 \pm 6.35$ & $64.49 \pm 4.59$ & $83.13 \pm 4.29$ & $63.91 \pm 5.46$ & $80.82 \pm 4.79$ \\
\hline $\begin{array}{l}\text { Research } \\
\text { group } \\
(n=74)\end{array}$ & $61.03 \pm 6.41$ & $85.57 \pm 5.39$ & $64.19 \pm 5.94$ & $84.93 \pm 5.71$ & $64.80 \pm 4.82$ & $85.74 \pm 4.49$ & $64.22 \pm 5.99$ & $83.47 \pm 5.10$ \\
\hline$\chi^{2} / t$ & 0.7335 & 3.0934 & 0.6624 & 2.2406 & 0.3933 & 3.5488 & 0.3227 & 3.1971 \\
\hline$P$ & 0.4644 & 0.0024 & 0.5088 & 0.0266 & 0.6947 & 0.0005 & 0.7474 & 0.0017 \\
\hline
\end{tabular}

Note: Data in bold indicates that the difference is statistically significant.

Table 5 Incidence of Complications and One-Year Recurrence Rate

\begin{tabular}{|l|c|c|c|c|c|c|}
\hline & $\begin{array}{c}\text { Postoperative } \\
\text { Infection }\end{array}$ & Cysthemorrhagia & Cystospasm & Urethrostenosis & $\begin{array}{c}\text { Total } \\
\text { Incidence }\end{array}$ & $\begin{array}{c}\text { One-Year } \\
\text { Recurrence Rate }\end{array}$ \\
\hline Control group $(\mathrm{n}=69)$ & $3(4.35)$ & $5(7.25)$ & $4(5.80)$ & $3(4.35)$ & $15(21.74)$ & $32(46.38)$ \\
Research group $(\mathrm{n}=74)$ & $1(1.35)$ & $2(2.70)$ & $2(2.70)$ & $2(2.70)$ & $7(9.46)$ & $22(29.73)$ \\
$\chi^{2 / t}$ & & & & 4.1361 & 4.2101 \\
$\mathrm{P}$ & & & & & $\mathbf{0 . 0 4 2 0}$ & $\mathbf{0 . 0 4 0 2}$ \\
\hline
\end{tabular}

Note: Data in bold indicates that the difference is statistically significant.

plasma, which achieves the purpose of bladder tumor resection through electrified cutting and coagulation effect, thus causing less trauma to patients, reducing OT, relieving patients' pain and facilitating patient recovery. ${ }^{31}$ The traditional $\mathrm{PC}$, as an open surgery, is more difficult to operate and can cause larger wounds to patients during the operation, which aggravates their burden and is not conducive to the rapid postoperative recovery of patients. ${ }^{32}$ After observing serum levels of inflammatory factors before and 7 days after operation, it was found that TNF- $\alpha$, IL-6, IL-8 were lower and IL-10 was higher in patients who underwent PKRBT. The main reasons are that PC as an open operation, exposes the abdominal cavity to air during the operation, coupled with the weak constitution and poor immune function of elderly patients as well as certain losses caused by the operation on the body, leading to their susceptibility to bacterial infection. ${ }^{33}$ IL-6 is a cytokine produced by lymphocytes, which can lead to the progression of inflammation in the body. ${ }^{34} \mathrm{TNF}-\alpha$, a cytokine that can directly kill tumors, has strong proinflammatory, antiviral and immunoregulation effects. ${ }^{35}$ IL-8 is an important angiogenic factor 
that can be secreted by bladder tumor cells. ${ }^{36}$ While IL-10, a recognized inflammatory and immunosuppressive factor, is a multi-cell-derived and multi-functional cytokine that modulates cell growth and differentiation, thus participating in inflammatory and immune responses. ${ }^{37}$ From the above results, we can find that PKRBT has huge advantages over PC. PKRBT is low-temperature $\left(40-70^{\circ} \mathrm{C}\right)$ cutting, with weak heat permeability, low probability of bladder muscle perforation, ${ }^{38}$ and obvious hemostatic effect. It may be due to the fact that transurethral resection is helpful to produce gasification layer and coagulation layer, which can significantly inhibit the occurrence of blood vessel hemorrhage, and effectively occlude small blood vessels and lymphatic vessels, contributing to the prevention of tumor cell metastasis. ${ }^{39}$ In addition, patients who received PKRBT had higher PSQI scores 7 days after surgery, lower SAS and SDS scores at 6 months after follow-up, and higher QOL after the 1-year follow-up. As we all know, surgery is easy to produce adverse emotions for some patients who lack relevant understanding of their own diseases and surgery. In addition, the degree and time of postoperative recovery have a great influence on patients' mentality. Compared with PC, PKRBT is less traumatic and patients face less postoperative recovery pressure, which can significantly alleviate their anxiety and depression.

Finally, the incidence of postoperative complications and 1-year recurrence rate were found to be lower in patients undergoing PKRBT, suggesting that PKRBT has obvious advantages in the treatment of BC and can reduce the recurrence rate. PKRBT is a new method to treat $\mathrm{BC}$ in clinical practice in recent years. Because the current does not pass through the human body during operation, there is less stimulation to the neuromuscles, reducing the incidence of obturator nerve reflex and the risk of bladder perforation. Although both PC and PKRBT can remove most visible tumors, their ability to remove tumors at the microscopic level is debatable. Open operation has no obvious advantage in this respect, while PKRBT is basically mature, with a clearer visual field under the microscope and better judgment of microscopic lesions, which can improve the surgical outcomes of patients. ${ }^{40}$ However, it has also been reported that $9 \%-49 \%$ of $\mathrm{BC}$ was underestimated during the first PKRBT. Therefore, it is necessary to master surgical techniques during the resection, which is an important guarantee for effectively controlling complications and improving clinical efficacy. $^{41}$

\section{Conclusion}

To sum up, PKRBT is effective in the treatment of BC and is worthy of promotion in clinical practice, as it can significantly improve the general surgical conditions of patients, relieve their bad mood, improve the long-term QOL to some extent, and lower postoperative complications and one-year recurrence rate. However, this study still has some deficiencies. Despite the sample size calculation, the sample size still needs to be expanded. In addition, the follow-up time of patients should be extended to obtain more accurate long-term efficacy, which would better support the results of this study.

\section{Author Contributions}

All authors made a significant contribution to the work reported, whether that is in the conception, study design, execution, acquisition of data, analysis and interpretation, or in all these areas; took part in drafting, revising or critically reviewing the article; gave final approval of the version to be published; have agreed on the journal to which the article has been submitted; and agree to be accountable for all aspects of the work.

\section{Disclosure}

The authors declare that they have no conflicts of interest.

\section{References}

1. Jordan B, Meeks JJ. T1 bladder cancer: current considerations for diagnosis and management. Nat Rev Urol. 2019;16(1):23-34. doi:10.1038/s41585-018-0105-y

2. Lenis AT, Lec PM, Chamie K. Bladder cancer: a review. JAMA. 2020;324(19):1980-1991. doi:10.1001/jama.2020.17598

3. Wu P, Zhang G, Zhao J, et al. Profiling the urinary microbiota in male patients with bladder cancer in China. Front Cell Infect Microbiol. 2018;8:167. doi:10.3389/fcimb.2018.00167

4. Liu X, Jiang J, Yu C, et al. Secular trends in incidence and mortality of bladder cancer in China, 1990-2017: a joinpoint and age-period-cohort analysis. Cancer Epidemiol. 2019;61:95-103. doi:10.1016/j. canep.2019.05.011

5. Sung H, Ferlay J, Siegel RL, et al. Global cancer statistics 2020: GLOBOCAN estimates of incidence and mortality worldwide for 36 cancers in 185 countries. CA Cancer J Clin. 2021;71(3):209-249. doi: $10.3322 /$ caac. 21660

6. Malats N, Real FX. Epidemiology of bladder cancer. Hematol Oncol Clin. 2015;29(2):177-189. doi:10.1016/j.hoc.2014.10.001

7. Guidance N. Bladder cancer: diagnosis and management of bladder cancer. BJU Int. 2017;120(6):755-765.

8. Recchia F, Candeloro G, Desideri G, et al. Triple-negative breast cancer: multipronged approach, single-arm pilot Phase II study. Cancer Med. 2012;1(1):89-95. doi:10.1002/cam4.3

9. Cumberbatch MGK, Jubber I, Black PC, et al. Epidemiology of bladder cancer: a systematic review and contemporary update of risk factors in 2018. Eur Urol. 2018;74(6):784-795. doi:10.1016/j. eururo.2018.09.001 
10. Farling KB. Bladder cancer: risk factors, diagnosis, and management. Nurse Pract. 2017;42(3):26-33. doi:10.1097/01.NPR.00005122 $51.61454 .5 \mathrm{c}$

11. Sanli O, Dobruch J, Knowles MA, et al. Bladder cancer. Nat Rev Dis Primers. 2017;3(1):1-19.

12. Feki-Tounsi M, Hamza-Chaffai A. Cadmium as a possible cause of bladder cancer: a review of accumulated evidence. Environ Sci Poll Res. 2014;21(18):10561-10573. doi:10.1007/s11356-014-2970-0

13. Koutros S, Decker KL, Baris D, et al. Bladder cancer risk associated with family history of cancer. Int J Cancer. 2021;148(12):2915-2923. doi:10.1002/ijc.33486

14. Woldu SL, Bagrodia A, Lotan Y. Guideline of guidelines-non-muscle invasive bladder cancer. BJU Int. 2017;119(3):371. doi:10.1111/ bju. 13760

15. Chang SS, Boorjian SA, Chou R, et al. Diagnosis and treatment of non-muscle invasive bladder cancer: AUA/SUO guideline. $J$ Urol. 2016;196(4):1021-1029. doi:10.1016/j.juro.2016.06.049

16. Patel VG, Oh WK, Galsky MD. Treatment of muscle-invasive and advanced bladder cancer in 2020. CA Cancer J Clin. 2020;70 (5):404-423. doi:10.3322/caac.21631

17. Mirzaei S, Paskeh MDA, Hashemi F, et al. Long non-coding RNAs as new players in bladder cancer: lessons from pre-clinical and clinical studies. Life Sci;2021. 119948. doi:10.1016/j.1fs.2021.119948

18. Ashrafizadeh M, Zarrabi A, Samarghandian S, Najafi M. PTEN: what we know of the function and regulation of this onco-suppressor factor in bladder cancer? Eur J Pharmacol. 2020;881:173226. doi:10.1016/ j.ejphar.2020.173226

19. Bilim V, Hoshi S. Prostatic urethra recurrence after transurethral resection of bladder tumor (TURBT) for non-muscle-invasive bladder cancer (NMIBC). Clin Case Rep. 2022;10(1):e05256. doi:10.1002/ccr3.5256

20. Li K, Xu Y, Tan M, Xia S, Xu Z, Xu D. A retrospective comparison of thulium laser en bloc resection of bladder tumor and plasmakinetic transurethral resection of bladder tumor in primary non-muscle invasive bladder cancer. Lasers Med Sci. 2019;34(1):85-92. doi:10.1007/ s10103-018-2604-8

21. Knoedler J, Frank I. Organ-sparing surgery in urology: partial cystectomy. Curr Opin Urol. 2015;25(2):111-115. doi:10.1097/ MOU.0000000000000145

22. Mor V, Laliberte L, Morris JN, Wiemann M. The Karnofsky performance status scale: an examination of its reliability and validity in a research setting. Cancer. 1984;53(9):2002-2007. doi:10.1002/10970142(19840501)53:9<2002::AID-CNCR2820530933>3.0.CO;2-W

23. Shadpour P, Zamani M, Aghaalikhani N, Rashtchizadeh N. Inflammatory cytokines in bladder cancer. J Cell Physiol. 2019;234 (9):14489-14499. doi:10.1002/jcp.28252

24. Backhaus J, Junghanns K, Broocks A, Riemann D, Hohagen F. Testretest reliability and validity of the Pittsburgh Sleep Quality Index in primary insomnia. $J$ Psychosom Res. 2002;53(3):737-740. doi:10.1016/S0022-3999(02)00330-6

25. Dunstan DA, Scott N. Norms for Zung's self-rating anxiety scale. BMC Psychiatry. 2020;20(1):1-8. doi:10.1186/s12888-019-2427-6

26. Yue T, Li Q, Wang R, et al. Comparison of Hospital Anxiety and Depression Scale (HADS) and Zung Self-Rating Anxiety/Depression Scale (SAS/SDS) in evaluating anxiety and depression in patients with psoriatic arthritis. Dermatology. 2020;236(2):170-178. doi:10.1159/ 000498848
27. Devilliers H, Amoura Z, Besancenot J-F, et al. Responsiveness of the 36-item short form health survey and the Lupus Quality of Life questionnaire in SLE. Rheumatology. 2015;54(5):940-949. doi:10.1093/rheumatology/keu410

28. Hamad J, McCloskey H, Milowsky MI, Royce T, Smith A. Bladder preservation in muscle-invasive bladder cancer: a comprehensive review. Int Braz J Urol. 2020;46:169-184. doi:10.1590/s1677-5538. ibju.2020.99.01

29. Ericson KJ, Murthy PB, Bryk DJ, et al. Bladder-sparing treatment of nonmetastatic muscle-invasive bladder cancer. Clin Adv Hematol Oncol. 2019;17(12):697-707.

30. Abotaleb AA, Kandeel WS, Elmohamady B, Noureldin YA, ElShaer W, Sebaey A. Bipolar plasma kinetic enucleation of non-muscle-invasive bladder cancer: initial experience with a novel technique. Arab J Urol. 2017;15(4):355-359. doi:10.1016/j. aju.2017.07.001

31. Jiang Y, Bai X, Zhang X, et al. Comparative study of the effectiveness and safety of transurethral bipolar plasmakinetic enucleation of the prostate and transurethral bipolar plasmakinetic resection of the prostate for massive benign prostate hyperplasia (>80 mL). Med Sci Monitor. 2020;26:e921272-921271. doi:10.12659/MSM.921272

32. Peak TC, Hemal A. Partial cystectomy for muscle-invasive bladder cancer: a review of the literature. Transl Androl Urol. 2020;9 (6):2938. doi:10.21037/tau.2020.03.04

33. Haider M, Ladurner C, Mayr R, et al. Use and duration of antibiotic prophylaxis and the rate of urinary tract infection after radical cystectomy for bladder cancer: results of a multicentric series. Paper presented at: Urologic Oncology: Seminars and Original Investigations 2019.

34. Hirano T. IL-6 in inflammation, autoimmunity and cancer. Int Immunol. 2021;33(3):127-148. doi:10.1093/intimm/dxaa078

35. Patel HJ, Patel BM. TNF- $\alpha$ and cancer cachexia: molecular insights and clinical implications. Life Sci. 2017;170:56-63. doi:10.1016/j. lfs.2016.11.033

36. Alfaro C, Sanmamed MF, Rodríguez-Ruiz ME, et al. Interleukin-8 in cancer pathogenesis, treatment and follow-up. Cancer Treat Rev. 2017;60:24-31. doi:10.1016/j.ctrv.2017.08.004

37. Mannino MH, Zhu Z, Xiao H, Bai Q, Wakefield MR, Fang Y. The paradoxical role of IL-10 in immunity and cancer. Cancer Lett. 2015;367(2):103-107. doi:10.1016/j.canlet.2015.07.009

38. Habib EI, ElSheemy MS, Hossam A, et al. Holmium laser enucleation versus bipolar plasmakinetic resection for management of lower urinary tract symptoms in patients with large-volume benign prostatic hyperplasia: randomized-controlled trial. $J$ Endourol. 2021;35 (2):171-179. doi:10.1089/end.2020.0636

39. Cha EK, Donahue TF, Bochner BH. Radical transurethral resection alone, robotic or partial cystectomy, or extended lymphadenectomy: can we select patients with muscle invasion for less or more surgery? Urol Clin. 2015;42(2):189-199. doi:10.1016/j.ucl.2015.02.003

40. Akand M, Muilwijk T, Raskin Y, De Vrieze M, Joniau S, Van Der Aa F. Quality control indicators for transurethral resection of nonmuscle-invasive bladder cancer. Clin Genitourin Cancer. 2019;17(4): e784-e792. (). doi:10.1016/j.clgc.2019.04.014

41. Luu DT, Duc NM, My T-T-T, Ly -T-T, Bang LV, Lenh B-V. Extraperitoneal bladder perforation secondary to transurethral resection of bladder tumor. Radiol Case Rep. 2021;16(4):811-814. doi:10.1016/j.rader.2021.01.035 


\section{Publish your work in this journal}

Cancer Management and Research is an international, peer-reviewed open access journal focusing on cancer research and the optimal use of preventative and integrated treatment interventions to achieve improved outcomes, enhanced survival and quality of life for the cancer patient.

The manuscript management system is completely online and includes a very quick and fair peer-review system, which is all easy to use. Visit http://www.dovepress.com/testimonials.php to read real quotes from published authors.

Submit your manuscript here: https://www.dovepress.com/cancer-management-and-research-journal 